\title{
Pest Detection Expert System And Method Using Bayes Rice Diseases
}

\author{
Wiwin Cindytia Wahyuni ${ }^{1}$, Arjon Samuel Sitio ${ }^{2}$ \\ .2 Engineering Informatics Program, STMIK Pelita Nusantara Medan, Jl. Iskandar Muda 1 \\ Medan, North Sumatra 20154, Indonesia \\ E-mail:wiwincindytia7@gmail.com
}

\begin{abstract}
Abstrac -Indonesia is included in an agricultural country that is rich in agriculture, fertile land in Indonesia Allows for the growth of various types of plants, one of the which is rice. But in the cultivation of rice plants, it will never be separated from pests and diseases of rice plants, so that the growth of rice plants is not optimal. Due to the large number of pests and diseases that can attack rice plants, it is Necessary to take proper care in dealing with pests and diseases of rice plants to avoid losses that can result in reduced production of rice plants. Therefore an expert system was created which was expected to help farmers in consulting about diseases and pests contained in their rice plants to the experts without having to meet with experts directly. In its identification,
\end{abstract}

Keywords : Expert systems, disease, pest, Bayes

\section{Pendahuluan}

Rice (Oryza sativa L.) is a food commodity that gets top priority in agricultural development. In rice cultivation, will never be separated from the name of pests and diseases of rice plants so as to make the growth of rice plants to be not optimal. Due to the many pests and diseases that can attack the rice plant, it would require precise handling in dealing with pests and diseases of rice plants to avoid damages that could result in reduced production of rice plants. ${ }^{1]}$

Expert System is a computer program that adopts the knowledge of an expert. Expert systems are very helpful in making a decision, this expert system can collect and store the knowledge of one or several experts in the knowledge base (Knowledge Base). [2]

The use of Bayes Theorem to conclusions because Bayes method provides a fundamental way to incorporate external information into the formula of probability analysis. This process begins with an existing probability distribution for a given set of data analyzed. Of this system is expected to help the farmers to consult on diseases and pests found in rice crops them to the experts. [3]

\section{Theory}

\subsection{Expert system}

Expert System is an artificial intelligence program that combines the knowledge base to base inference system to mimic an expert. (Zufian Azmi, 2017). Expert systems in place to support problem-solving activities. In addition the expert system can also serve as a clever assistant of an expert. The basic concept of expert system contains expertise, experts, transfer of expertise, inference, rules, and the ability to explain.

\subsection{Bayes theorem}

According Zulfian Azmi (2017) explains that Bayesian methods are used to meenghitung probability of occurrence of an event based on the effect obtained from the observation. Bayesian methods provide a fundamental way to incorporate external information into the formula of probability analysis. This process begins with an existing probability distribution for a given set of data analyzed. In general, Bayes theorem is expressed as:

Where :

$$
P A \mid B \quad=\frac{P B A P(A)}{P(B)}
$$

$$
\begin{array}{ll}
\mathrm{P}(\mathrm{A} \mid \mathrm{B}) & =\text { Results are sought } \\
\mathrm{P}(\mathrm{A}) & =\text { weights Bayes } \\
\mathrm{P}(\mathrm{B}) & =\text { Total Symptom } \\
\mathrm{P}(\mathrm{B} \mid \mathrm{A}) & =\text { weights Symptoms }
\end{array}
$$

\section{Research methods}


Research framework is the concept of a research that connects the visualization of the variables premises other variables, so that research be systematically arranged and can be accepted by all parties. The framework research this time will use the Waterfall Model.

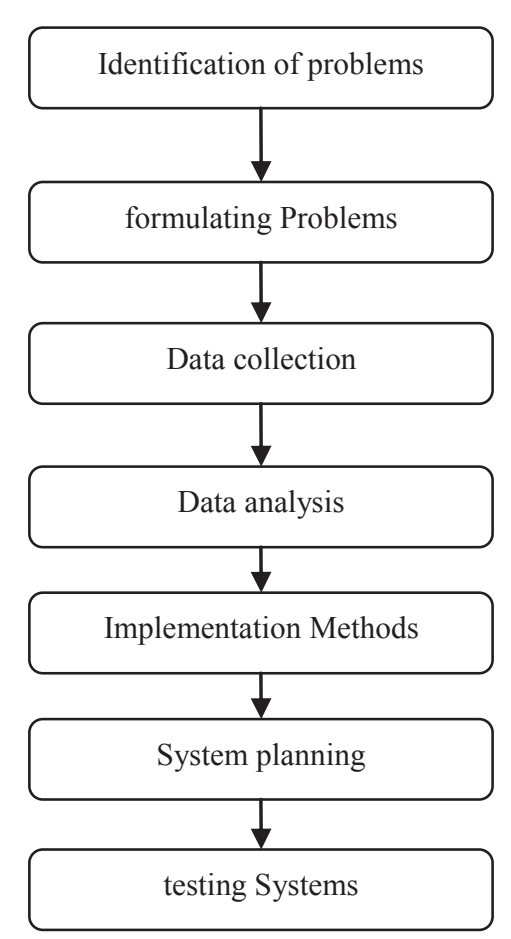

\subsection{Stage Data Collection}

Picture 1. Framework Research

The collection of data used in this study consisted of primary and secondary data. The primary data was done by face to face and interviewed village agricultural extension, while secondary data obtained from various sources such as books, journals, and the Internet.

\section{2. analysis Methods}

The analysis method is the method to be applied in the research process and are determined by the research method used. In this study using an expert system MethodsBayes ie calculate the probability of occurrence of an event based on the effect obtained from the observation.

\subsection{System planning}

The system design is to design or designing a good system, the contents of the operation steps in data processing. Designing systems using Web programming with PHP and HTML programming language and MySQL database with XAMPP. In such a system there will be a design expert system using the methodBayes.

\subsection{Implementation}

implementation is an application or action taken based on the plan that has been prepared or made carefully and in detail earlier. At this stage is a continuation of the implementation phase and will be tested with our data processing practices with Method Bayes which is already implemented.

\subsection{System planning}

Stages of system design that will be built using the Unified Modeling Language (UML), which supports the modeling concepts based programming Object Oriented Programming (OOP) as would be applied at the stage of writing program code. At this stage will be obtained documentation of modeling, among others: Use Case Diagram, Use Case Scenario, Sequence Diagram, Activity Diagram, Class Diagram and Entity Relationship Diagram (ERD).

\section{Analysis And Design}

\subsection{Analysis}

The analysis aims to identify issues that exist in the system. This analysis is needed as a basis for the system design stage. In building an expert system to do some analysis phase is to determine the problems the 
system to be built, gather the data needed to build the system, presenting knowledge into the knowledge base, production and traceability rules.

\section{a. Analysis Bayes Method}

Bayesian methods used to calculate the probability of occurrence of an event based on the effect obtained from the observation. Bayesian methods are used to implement the results in determining the type of pests and diseases of rice.

table 1

Diseases of Rice

\begin{tabular}{cl}
\hline Code & \multicolumn{1}{c}{ Disease name } \\
\hline P01 & Leaf blight \\
P02 & Leaf spotting \\
P03 & Stem rot \\
P04 & Fusarium diseases \\
P05 & Leaf sheaths foul \\
\hline
\end{tabular}

Table 2.

Rice Plant Disease Symptoms Data and Value Probability

\begin{tabular}{lll}
\hline Code & symptom & Weight \\
\hline GP01 & Reddish yellow leaf & 0.06 \\
GP02 & Plants wither and die & 0.03 \\
GP03 & Rotten rice seeds germinate and then die moment & 0.03 \\
GP04 & Rotten rice and dries & 0.04 \\
GP05 & Seeds have patches but still contain & 0.01 \\
GP06 & Upih leaf necrotic spots on the outer & 0.04 \\
GP07 & Dark patches of raised and gradually widens & 0.03 \\
GP08 & Trunk fall before cooking & 0.06 \\
GP09 & Panicle and immature seed brownish & 0.04 \\
GP10 & The leaves droop & 0.01 \\
GP11 & Root decay & 0.03 \\
GP12 & Spotting grow until the flag leaf & 0.01 \\
GP13 & Spotting begins at the surface of the water near the midrib first then expand to & 0.04 \\
the midrib or leaves the top & 0.03 \\
GP15 & $\begin{array}{l}\text { Oval or elliptical with a length of 1-3 cm } \\
\text { easily separated }\end{array}$ & 0.01 \\
GP16 & $\begin{array}{l}\text { In the humid state of patches grow white threads or mycelia and infect the leaf } \\
\text { midrib / leaf }\end{array}$ & 0.04 \\
\hline
\end{tabular}

table 3

Pests of Rice

\begin{tabular}{cl}
\hline Code & \multicolumn{1}{c}{ name Hama } \\
\hline H01 & Rat \\
H02 & Winches Trunk / sundep \\
H03 & Golden snail \\
H04 & wereng \\
H05 & Walang Sangit \\
H06 & Bird \\
\hline
\end{tabular}

Table 4.

Symptoms Data Rice Plant Pests and Probability Value

\begin{tabular}{llc}
\hline Code & \multicolumn{1}{c}{ symptom } & Weight \\
\hline GH01 & The reduced production of rice & 0.01 \\
GH02 & Middle leaves or shoots of plants will die & 0.01 \\
GH03 & Rice tillers become stunted and die & 0.04 \\
GH04 & Malai Hampa & 0.03 \\
GH05 & Shoots of rice straw becomes dry, yellow and easy to remove & 0.01 \\
GH06 & The loss of rice seeds per plant & 0.07 \\
GH 07 & Rice discharged from the leaf to the stem of young rice & 0.03 \\
GH08 & Rice was dry, burning & 0.04 \\
GH09 & Rice growth becomes stunted & 0.04 \\
GH10 & Bending the leaves so that the plant growth appears to be normal & 0.03 \\
GH11 & Dark green leaves & 0.04 \\
\hline
\end{tabular}

